\title{
Investigation of preferred leadership behaviors in sport and empathic tendency with regards to different variables
}

\author{
Gaye ERKMEN, Mehibe AKANDERE
}

Faculty of Sport Sciences, Selçuk University, Konya, Turkey.

Address Correspondence to G. Erkmen, e-mail: gerkmen9@mail.com

\begin{abstract}
This study was conducted in order to explore the emphatic tendencies of students receiving education at the School of Physical Education and Sport as well as the leadership behaviors they prefer with regard to different variables. The sampling of the study involved a total of 361 students with 138 female and 223 male students. Empathic tendencies Scale (ESS) preferred leadership behavior form of Leadership for Sport Scale were used for data collection. In the analysis of data, depending on the variables, independent samples t-test, one-way variance analysis and Pearson product-moment correlation coefficient method was utilized. In order to determine the source of differentiation in findings which were significant differences as ANOVA was conducted. In consequence of the analyses, whereas no difference was found among empathic tendency scores with regard to gender variable, significant difference was found in sub-dimensions of preferred leadership behaviors; social support, democratic behavior, autocrative behavior. With regard to sport type variable, among the empathic tendency scores a statistically significant difference was observed in democratic behavior sub-dimension. As a result of the analysis carried out in an effort to determine the correlation between empathic tendency and preferred leadership behavior, positive and significant relationships were observed between social support, positive feedback and training and instruction sub-dimensions and empathic tendencies. Findings indicated that individuals who were captain have higher empathic tendency scores than those who were not.
\end{abstract}

Keywords: Empathic tendency, preferred leadership behaviors, sport.

\section{INTRODUCTION}

In struggle for life since times humanity existed, individuals who influence other humans with their personality traits in social structure of societies and smallest human groups have been one step ahead of others. As time progressed individuals who stood out in a different position started to be called 'leader'. As a result of the researches and works on the notion of 'leadership' has become the focus of communities in the path to success. The researches about leadership revealed that a potential leader intended to expose the tendencies and attitudes the leadership behavior required. In these works, the traits influencing leadership was researched and theorized, through which different leader types were discovered in accordance with different views.

Alongside the traits possessed by the leader, the concept of empathy, provided that it connects, is thought be prominent in the process of leading the group members and have an effective role in bringing feeling of mutual trust among the group members. Therefore the influence of empathy on a successful leader is rather significant to form a positive communication between a leader and the individuals he or she leads.

Defining success and directing social bonds in human relations, empathy is regarded as a significant and necessary skill that preserves the concept of community. Having described as the capacity to place oneself in another's position and understand their peculiar inner world precisely stating their feelings and thoughts (8), empathy has a great importance in our daily lives. This mechanism provides the individuals with the possibility to understand and have an idea about other inner worlds and thoughts.

Dökmen (8) regards empathy in two aspects as empathic tendency (ET) and empathic tendency (ET). Empathic tendency forms the emotional aspect of 
empathy and reveals the individual's potential of empathizing. Empathic tendency, on the other hand, is expressed as an individual's potential to establish empathy (7).

Proliferation of teamwork, rapid-spread of globalization and the gradual increase in need for talented individuals all prove that empathy must be a significant component of leadership (13). Empathy plays a crucial and effective role in the ensuring communication and mutual trust between the leader and the followers (9). It is also argued that empathic leadership improves the communication and interaction among the team members (9).

Freedman (10) explains empathy, "As a leader, increasing empathy is a key to understanding others and forming enduring and trusting relationships. Leaders who are not empathic may miss critical insight into others and can be seen as self-interested, cold, or not trustworthy" (p. 186).

Empathy connotes taking group members' feelings into consideration in the resolution process alongside other factors. Empathic leaders are individuals who go beyond showing empathy to people around them and use their knowledge skillfully to develop their teammates (12). It is assumed that the leader that could keep the team members in interaction with each other in sport, serving a common purpose to achieve a goal and using empathy in communication, has a great share in team's success along with teammates. In short it is anticipated that team members who could empathize might have stronger relations with leaders who could empathize and they might understand better what the leaders expect of them precisely, as a result of which they might be more successful and have a higher level of satisfaction.

This study purpose was to investigate preferred leaderships behaviors in empathic tendency and sport with regard to different variables. This study's aim was also to reveal whether there was a correlation between the individual's preferred behaviors and their empathic tendency level. In the research answers to the following questions were sought.

- Is there any difference between participants' empathic tendencies and their preferred leadership behaviors with respect to gender?
* Is there any difference between participant's empathic tendencies and their preferred leadership behaviors with regard to sport type?

* Is there any difference between participant's empathic tendencies and their preferred leadership behaviors with regard to captain status?

* Is there a relationship between participant's empathic tendencies and their preferred leadership behaviors?

\section{MATERIAL \& METHODS}

\section{Participants}

The sampling of this work consists of a total of 361 (138 female, 233 male) students studying School of Physical Education and Sports with 121 students from physical education and sport department, 120 from management department and 120 from coaching department. The mean age of the participants was 21.82 (SD = 2.13) and the participants had been working out for an average 6.77 years. 178 of the participants had captained in their respective sport branch.

\section{Measures}

Data collection demographic information form designed by the researcher, Empathic Tendency Scale (ETS) designed by Dökmen (6) and preferred leadership behavior form of Leadership for Sport Scale designed by Chelladurai\&Saleh (4) and adapted by Tiryaki (18) were used in data collection.

Demographic information Form: The data form used in the study include questions about the participants' gender, age, department, sport branch, how long they had been doing sport and whether they had captained a team or not.

Empathic Tendency Scale (ETS): ETS was designed by Dökmen (6) to gauge individuals' empathizing potential in the daily life. ETS consisted of 20 items were rated 5 point rating scale scored from 1 to 5 . The total point exposes the subjects' empathic tendency points. A high score asserts high empathic tendency whereas a low score asserts low empathic tendency. Cronbach Alpha reliability co-efficient was found to be .72 for present study.

Leadership for Sport Scale- Preferred Leader Behavior Form: Designed by Chelladurai\&Saleh (4), 
preferred leadership behavior form of Leadership for Sport Scale is composed of 40 items each of which are rated using 5 point rating scale. The Scale consists of five sub-dimensions that describe leader behaviors; Training and instruction, Democratic Behavior, Autocrative Behavior, Social Support and Positive Feedback. The behavior form preferred by the athletes was translated into Turkish by Tiryaki (18) and reliability testing was carried out. Cronbach Alpha internal consistency values of the scale was respectively .73 for education and training, .71 for democratic behavior, .60 for authoritative behavior, .63 for social support and .65 for positive feedback.

\section{Data Analysis}

In the analysis of data, depending upon variables independent group $t$ test and one-way variance analysis test were used. In order to determine the source of differentiation in findings that are significant difference as a result of variance analysis, Tukey test was conducted. Pearson product-moment correlation coefficient method was utilized to determine the correlation between empathic tendency points and preferred leadership behavior subdimensions. SPSS 15 programme was used in the analysis of data and significance level was regarded as $\mathrm{p}<.05$.

\section{RESULTS}

The statistical processes carried to determine whether the participants' empathic tendencies and preferred leadership behavior sub-dimensions differentiated significantly in terms of gender, empathic tendency levels, and branch variables and to reveal whether there was a significant correlation between empathic tendency and preferred leadership behavior sub-dimensions were included in this section.

Independent group $t$ test was applied to examine the participants' empathic tendency points and preferred leadership behaviors sub-dimensions with regard to gender variable.

It is seen as in Table 1, there was not a significant difference in empathic tendency scores in terms of gender $(t=1.045 ; \mathrm{p}>$.05). However, significant differences were observed in terms of gender variable in preferred leadership behaviors; social support $(\mathrm{t}=\mathrm{-}$ 2.345; $\mathrm{p}<.05)$, democratic behavior $(\mathrm{t}=2.018 ; \mathrm{p}<.05)$ and authoritative behavior $(\mathrm{t}=-3.508 ; \mathrm{p}<.05)$ subdimensions. Positive feedback $(t=-1.128 ; p>.05)$ and education and training $(t=1.036 ; \mathrm{p}>.05)$ subdimensions were not significantly differentiated in terms of gender variable $(\mathrm{p}>.05)$.

Variance analysis was conducted to examine differences between empathic tendency and preferred leadership behaviors with regard to sport types (individual sports, team sports and none) and the results were displayed on table 2 .

Table 1. The results of $t$ test of empathic tendency and preferred leader behavior sub-dimension with regard to gender.

\begin{tabular}{|c|c|c|c|c|c|}
\hline & Gender & Mean & SD & $t$ & $\mathrm{p}$ \\
\hline \multirow[t]{2}{*}{ Empathic tendency } & Female & 71.85 & 8.79 & \multirow{2}{*}{1.045} & \multirow{2}{*}{.247} \\
\hline & Male & 70.81 & 9.86 & & \\
\hline \multirow[t]{2}{*}{ Social support } & Female & 16.36 & 3.91 & \multirow{2}{*}{-2.345} & \multirow{2}{*}{$.020^{*}$} \\
\hline & Male & 15.48 & 4.21 & & \\
\hline \multirow[t]{2}{*}{ Democratic behaviour } & Female & 20.80 & 5.24 & \multirow{2}{*}{2.018} & \multirow{2}{*}{$.044^{*}$} \\
\hline & Male & 22.03 & 5.92 & & \\
\hline \multirow[t]{2}{*}{ Positive feedback } & Female & 10.90 & 3.01 & \multirow{2}{*}{-1.128} & \multirow{2}{*}{.260} \\
\hline & Male & 10.54 & 3.05 & & \\
\hline \multirow[t]{2}{*}{ Training and instruction } & Female & 19.48 & 4.41 & \multirow{2}{*}{1.036} & \multirow{2}{*}{.301} \\
\hline & Male & 20.03 & 5.36 & & \\
\hline \multirow[t]{2}{*}{ Autocrative behaviour } & Female & 13.08 & 2.81 & \multirow{2}{*}{-3.508} & \multirow{2}{*}{$.001^{*}$} \\
\hline & Male & 12.06 & 3.00 & & \\
\hline
\end{tabular}


Table 2. The ANOVA results of empathic tendency and preferred leadership behaviors by sport types.

\begin{tabular}{|c|c|c|c|c|c|c|c|c|}
\hline & \multicolumn{2}{|c|}{ Individual Sports } & \multicolumn{2}{|c|}{ Team Sports } & \multicolumn{2}{|c|}{ None } & \multirow{2}{*}{$\mathrm{F}$} & \multirow{2}{*}{$\mathrm{p}$} \\
\hline & $\mathrm{M}$ & SD & $\mathrm{M}$ & $\mathrm{SD}$ & $\mathrm{M}$ & SD & & \\
\hline Empathic tendency & 70.57 & 10.16 & 72.62 & 8.90 & 66.94 & 7.99 & 6.473 & $.002^{*}$ \\
\hline Social support & 16.02 & 4.22 & 15.54 & 3.87 & 16.19 & 4.71 & .389 & .678 \\
\hline Democratic behaviour & 20.68 & 4.91 & 22.25 & 5.94 & 21.81 & 6.85 & 3.137 & $.045^{*}$ \\
\hline Positive feedback & 10.44 & 2.95 & 10.81 & 3.10 & 10.89 & 3.06 & 1.055 & .349 \\
\hline Training and instruction & 19.93 & 5.35 & 19.53 & 4.42 & 20.65 & 6.01 & .205 & .815 \\
\hline Autocrative behaviour & 12.46 & 2.91 & 12.34 & 2.99 & 12.79 & 3.11 & 1.542 & .215 \\
\hline
\end{tabular}

Table 3. The correlation between empathic tendency and preferred leader behavior sub-dimensions.

Social support Democratic behaviour Positive feedback Training and instruction Autocrative behaviour

\begin{tabular}{llllll}
\hline Empathic tendency & $.123^{*}$ & .043 & $.136^{*}$ & $.138^{* *}$ & -.027 \\
\hline${ }^{*} \mathrm{p}<0.05 ;{ }^{* *} \mathrm{p}<0.01$. & & & &
\end{tabular}

As it is seen at Table 2, participants' empathic tendencies differentiated with regard to sport types ( $\mathrm{p}$ $=.002)$. A significant differentiation was observed in terms of gender variable in democratic behavior $(\mathrm{p}=$ .045) sub-dimension. Tukey test was conducted to pinpoint the source of differentiation in empathic tendency and democratic behavior sub-dimension. Findings indicated that there was a significant difference between individual sports' participants and team sports' participants in terms of their empathic tendency scores. It was observed that considering empathic tendency averages, team sports' participants have higher empathic tendency scores than individual sports' participants. In addition, a significant differentiation was also examined in democratic behavior dimension between team sports participants and those who do not play any branch of sport $(\mathrm{p}=$ $.002 ; \mathrm{p}<.05)$.

Observing empathic tendency scores regarding the captaincy status, it was seen that those who could captain significantly differ from those who could not $(t=3.748 ; p<05)$. It was also observed that the preferred leadership behaviours' did not differentiate significantly with regard to captaincy status.

The correlation analysis which was carried out to determine the correlation between student's empathic tendency scores and their preferred leadership behavior sub-dimensions is displayed on table 3.
A significant correlation was detected between empathic tendency and preferred leader behavior sub-dimensions; social support $(\mathrm{p}=.02 ; \mathrm{r}=.123)$, positive feedback $(\mathrm{p}=.01 ; \mathrm{r}=.136)$, education $(\mathrm{p}=.01$; $\mathrm{r}=.138)$. No significant correlation was found between democratic behavior and autocratic behavior and empathic tendency scores.

\section{DISCUSSION}

This study was conducted in order to examine the emphatic tendencies and the preferred leadership behaviors of students receiving education at the School of Physical Education and Sports with regard to different variables.

As a result of the study, there was not a significant difference between female and male participants' empathic tendency scores. Studies showed that females have been found to be more empathic than males (5), and women have a greater capacity for understanding others' thoughts and feelings than do men (14). This finding does not confirm previous studies' findings that showed gender differences in empathic tendency. Another result regarding the gender variable is that female and male participants significantly differentiate in social support, democratic behavior and autocratic behavior sub-dimensions of preferred leadership behavior. Inconsistent with the previous studies, female participants preferred more social support and autocratic behavior than male participants in the study. On the contrary, male participants preferred 
more democratic behavior than female participants. Chelladurai (2) has revealed that female athletes exhibit less autocratic behavior in comparison to males and expect more social support leader behavior than males. Conversely, female athletes were observed to expect more democratic leadership behavior of their coaches $(2,3,17)$. Another study stated (1) that male collegiate athletes showed preferences for coaches who displayed strong autocratic and social support behaviors where females showed preferences for coaches with strong situational consideration and training and instruction behaviors.

A significant difference was observed in empathic tendency scores with regard to sport type variable. While athletes involved in team sports had higher empathic tendency scores, those who were not involved in any type of sport had lower empathic tendency scores. It is thought that since team unity, movement in between team members and the relations among the group members is important; team members' empathic tendency could be high. Moreover, a significant difference was observed in terms of sport type variable in democratic behavior sub-dimension of the preferred leadership behavior. This difference was observed between athletes involved in team sports and those who were not involved in any type of sport. In team sports, collective movement of the team members, collective decision making and interaction between group members to attain the object is rendered possible through a democratic environment in group dynamics. On the contrary to present finding, studies $(15,17)$ showed that individual and independent sport athletes preferred a greater degree of democratic behaviour compared to team sport athletes.

Recently, many studies have been looking into athlete leadership (e.g. captains) to better understanding of different missions of players in team and individual sports. Since athlete leaders sharing similar values like coaches, empathy is also considered as an essential element for team captains. Therefore, this study also investigated participants' empathic tendency scores with regard to theirs captaincy status. Findings represented that individuals who were captain have higher empathic tendency scores than those who were not. Loughead and Hardy (16) stated that athlete leaders like team captains can have stronger leadership strengths in social support, positive feedback, and democratic behaviors than a coach. Although a significant difference was expected between preferred leadership behaviors and captaincy, preferred leadership behaviors sub-dimensions did not significantly differentiate with regard to captaincy status.

The correlation analysis was conducted to reveal the relationship between participants' empathic tendency scores and preferred leadership behaviors. According to findings, positive and weak correlations were detected between participants' tendency scores and social support, positive feedback and training and instruction dimensions. Social support dimension is characterized by a concern for the welfare of athletes, positive group atmosphere, and warm interpersonal relations with team members (4). This explanation might support that the relationship between empathic tendency and social support dimension. Further, positive feedback and training and instruction dimensions were positively related to empathic tendency in present study. These two dimensions might include also empathic emotions to improve athletes' performance by emphasizing and facilitating hard and strenuous training; instructing them in the skills, techniques, and tactics of the sport; clarifying and the relationship among the members; structuring and coordinating the members' activities; and recognizing and rewarding good performance (4). However, study findings were not demonstrated that there were significant relationships between participants' empathic tendency scores and democratic and autocratic behavior dimensions. Especially, it was expected that there would be relationships between democratic behavior as this dimension includes greater participation by the athletes in decisions pertaining to group goals, practice methods, and game tactics and strategies (4). Empathic emotions might facilitate to constitute a convenient environment to help build and strengthen relationships among coaches and team members. Further, it was expected that there was a significant and negative relationship between empathic tendency and autocratic behavior because this behaviour involves independent decision making and stresses personal authority (4).

When evaluating the results of this study, the limitedness's about the pattern of the study must be 
taken into account. Firstly, it is worth noting that the sampling of the study consisted of students receiving education at the School of Physical Education and Sports, which therefore limited generalizability of the study. Secondly, since reliability coefficients for subdimensions of the leadership for sport scale used in the study were low, it will come in useful for future studies to review the psychometric properties. Lastly, only the leader behaviors preferred by the participants were scaled in the study. It is believed that by scaling the leader behaviors displayed by participants, it will be better to correlate among their empathic tendencies. It is thought that considering this condition for future studies will provide more supportive results in terms of enucleating the correlation between empathic tendency and leader behavior.

In summary, empathy concept can be considered as an important skill that must be possessed by a leader that affects the interaction among coach and team members. The present study is just an initial study to investigate empathic tendency and preferred leadership behaviors with regard to gender, sport type and captaincy, and explore relationship between empathic tendency and preferred leadership behaviors. More studies should be conducted to examine in greater depth of this relationship.

\section{REFERENCES}

1. Beam J, Serwatka T, Wilson W. Preferred leadership of NCAA division I and II intercollegiate student-athletes, Journal of Sport Behavior, 2004; 27 (1), 3-17.

2. Chelladurai P, Leadership. In R. N. Singer, M. Murphey, \& L. K. Tennant (Eds.), Handbook of research on sport psychology, (pp. 647-671). New York: Macmillan, 1993.

3. Chelladurai P, Haggerty TR, Baxter P. R. Decision style choices of university basketball coaches and players. Journal of Sport and Exercise Psychology, 1989; 11, 201-215.
4. Chelladurai P, Saleh S.D. Dimensions of leader behavior in sports: Development of a leadership style, Journal of Sport Psychology, 1980; 2, 34-45.

5. Cohen D, Strayer J. Empathy in conduct-disordered and comparison youth, Developmental Psychology, 1996; 32: 988998.

6. Dökmen Ü. Empatinin yeni bir modele dayanılarak ölçülmesi ve psikodrama ile geliştirilmesi, Ankara Üniversitesi Eğitim Bilimleri Fakültesi Dergisi, 1988; 21(1-2): 155-190.

7. Dökmen Ü. Sanatta ve günlük yaşamda iletişim çatışmaları ve empati (4th ed.). İstanbul: Sistem Yayınc1lık, 1996.

8. Dökmen Ü. İletişim çatışmaları ve empati. Sistem Yayıncılık, İstanbul, 2005; s.152-154, 339-341.

9. Dubrin A. J. Leadership. Boston, New York: Hougton Mifflin Company, 2001.

10. Freedman J. At the heart of leadership. How to get results with emotional intelligence. San Mateo: Sixseconds, 2007.

11. Goleman D. Duygusal zeka, Varlık Yayınları, İstanbul, 1996; 40.

12. Goleman D. Lideri lider yapan nedir?, Mess Yayın, İstanbul, 2002; 25-28.

13. Goleman D. What makes a leader. In W. E. Robert L. Taylor, Military Leadership (pp. 53-68), Westview Press, 2005.

14. Klein KJK, Hodges S. D. Gender differences, motivation, and empathic accuracy: When it pays to understand. Personality and Social Psychology Bulletin, 2001; 27:720-730.

15. Lindauer J. R. A comparison of preferred leadership behavior of college athletes in individual and team sports. Unpublished Master's Thesis, University of Wisconsin-LaCrosse, 2000.

16. Loughead T, Hardy J. An examination of coach and peer leader behaviors in sport. Psychology of Sport and Exercise, 2005; 6, 303-312.

17. Terry PC, Howe B. L. Coaching preferences of athletes. Canadian Journal of Applied Sport Science, 1984; 9 (4), 188-193.

18. Tiryaki Ş. Spor için liderlik ölçeğinin Türk sporcularına uyarlanması çalışması, V. Uluslararası Spor Bilimleri Kongresi, 3-5 Kasım 2000; Hacettepe Üniversitesi, Ankara. 